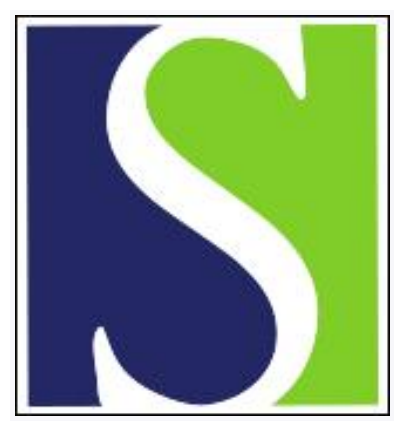

Scand J Work Environ Health 1994;20(4):294-300

https://doi.org/10.5271/sjweh.1395

Issue date: 01 Aug 1994

Noise exposure, noise annoyance, use of hearing protection devices and distress among blue-collar workers.

by Melamed S, Rabinowitz S, Green MS

Affiliation: Occupational Health and Rehabilitation Institute, Loewenstein Hospital, Raanana, Israel.

This article in PubMed: www.ncbi.nlm.nih.gov/pubmed/7801075

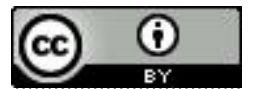




\title{
Noise exposure, noise annoyance, use of hearing protection devices and distress among blue-collar workers
}

\author{
by Samuel Melamed, PhD, ${ }^{1}$ Stanley Rabinowitz, PhD,,${ }^{1,}$ Manfred S Green, MD ${ }^{1,2}$
}

MELAMED S, RABINOWITZ S, GREEN MS. Noise exposure, noise annoyance, use of hearing protection devices and distress among blue-collar workers. Scand J Work Environ Health 1994;20: $294-300$.

OвJEctives - This study tested the hypotheses that, in high noise levels [ $\geq 85 \mathrm{~dB}(\mathrm{~A})]$, hearing protection devices are used largely by workers sensitive to noise, as reflected by reports of noise annoyance, and that the usage would reduce distress symptoms.

Metнons - Data collected from 1587 healthy male blue-collar workers included noise exposure level, noise annoyance, use of hearing protection devices, distress symptoms (somatic complaints and poststress irritability), and possible confounding by age, education and ethnic origin.

REsults - Multiple logistic regression results indicated that the use of hearing protection devices was related to noise exposure level [odds ratio (OR) $2.94,95 \%$ confidence interval (95\% CI) 2.58 3.30 ], but more so to high noise annoyance (OR 3.03, 95\% CI 2.77-3.29), even after control for age, education, and ethnic origin. No interaction was found between noise level and noise annoyance. These findings highlight the contribution of noise annoyance to the use of hearing protection devices. Of the $42.6 \%$ of workers using hearing protection devices in the presence of high ambient noise, $60 \%$ were highly annoyed. Noise-annoyed workers also tended to wear hearing protection devices even in low noise levels. The use of hearing protection devices was associated with lower distress symptoms among the low and moderately annoyed workers, but among the highly annoyed workers the reverse was true.

Conclusions - Thus, for the highly annoyed workers, the use of hearing protection devices was perhaps an additional source of stress. One immediate implication of this study is that future intervention procedures should focus on unannoyed workers who tend to use hearing protection devices less.

KEY TERMS - ambient noise, annoyance, blue-collar workers, hearing protectors, psychological distress.

Notwithstanding the fact that workers are generally aware of the detrimental effects of exposure to noise at levels of $85 \mathrm{~dB}(\mathrm{~A})$ and above $(1,2)$, studies have found that the prevention of hearing damage through the use of hearing protectors in industry is low, varying from $20 \%$ usage in some studies (3) to $30-$ $50 \%$ in others (4-6). Campaigns aimed at increasing the use of hearing protection devices have included behavioral, sanction, and conditioning procedures (7); enforcement of laws and administrative rules (8); and educational intervention (9). However, these interventions have had limited success.

Most studies have focused on reasons for the nonuse of hearing protection devices. Barriers for industrial workers' not using hearing protection devices at high noise exposure levels have been associated with a variety of factors. Use is sometimes unpopular with users because of incompatibility with other

Occupational Health and Rehabilitation Institute at Loewenstein Hospital, Raanana, Israel.

2 Sackler School of Medicine, Tel-Aviv University, Israel.

Reprint requests to: Dr S Melamed, Occupational Health and Rehabilitation Institute, PO Box 3, Raanana 43100, Israel headgear, irritation of the ear canal lining (10-13), feelings of discomfort, interference with job performance, and the psychological feeling that the continual wearing of hearing protection devices lowers a worker's prestige (14). Furthermore, interfering with communication and preventing workers from hearing appropriate warning signals have also been stated as reasons for noise-exposed individuals to reject hearing protection devices (15).

On the other hand, the question of why people do in fact use hearing protection devices on a regular basis has not received adequate attention. Only general reasons have been cited. These include noise exposure level (6), availability (16), and mandatory regulations and sanctions (7). However, these factors hardly explain individual differences in the use of hearing protection devices among workers exposed to the same ambient noise level and working under the same work regulations with hearing protection devices available.

Our study was designed to expand the knowledge on this topic and to investigate why workers use hearing protection devices. We decided to focus on one factor that has been suggested, but not systematically investigated, namely, that workers using hearing protection devices do so to reduce noise 
stress $(6,17)$. Noise has been shown to be a general and nonspecific stressor $(18-20)$ that includes a host of psychological $(18,21,22)$ and physiological $(23-$ 26) responses. Nevertheless some evidence indicates that there are workers who are more susceptible to noise stress than others. These workers can apparently be identified by their reports of noise annoyance. Noise annoyance refers to subjective ratings of the noise as undesirable, irritating, and disturbing $(22,27)$. Noise annoyance has been found to be independent of the ambient noise level $(6,18,28)$, but it is related to subjective noise sensitivity $(27,29)$.

Supporting evidence for using noise annoyance as a marker of worker sensitivity to noise comes from our recent large study of blue-collar workers ( 1680 men and 688 women) showing that distress symptoms (somatic complaints and poststress irritability) increased significantly with increased noise exposure levels only among workers who reported high noise annoyance. Furthermore, such workers also displayed higher rates of accidents and sickness absence (28).

Thus it seems likely that, in the presence of high ambient noise [>85 $\mathrm{dB}(\mathrm{A})]$, workers expressing high noise annoyance would use hearing protection devices to a greater extent than those expressing low noise annoyance. Results in this direction were reported by Van Dijk et al (6). However, they did not report statistical significance nor the extent to which noise annoyance increased the use of hearing protection devices. Our study was designed to elucidate these points. In particular, we wished to investigate whether the use of hearing protection devices is mainly an outcome of the noise exposure level, noise annoyance, or their interaction. In addition, the study was designed to investigate whether noise-annoyed workers using hearing protection devices would, in fact, display less distress symptoms than workers not using hearing protection devices.

\section{Subjects and methods}

\section{Subjects}

The target study group was 2497 male blue-collar workers aged 20-64 years who participated in the "Cardiovascular Occupational Risk Factors Detection in Israel Study" (CORDIS) and could be classified clearly as to low and high noise-exposure levels. CORDIS was a multidisciplinary, cross-sectional and longitudinal epidemiologic investigation aimed at identifying occupational risk factors for cardiovascular disease. Data collected from each participant covered a multitude of medical, biochemical, ergonomic, environmental, and psychological variables. Participation was on a voluntary basis, free of charge, and on company time. The response rate was over $60 \%$; failure to participate was largely due to technical and logistic factors rather than to workers' refusal. The present study was based on data collected during phase I of the project (1985-1987) from 21 manufacturing plants: six textile factories, five moderately heavy metalworks, two light metal industries, three plywood and formica plants, two electronics plants, two food product factories, and one printing press. The definition of blue-collar work has been presented elsewhere (28).

\section{Exclusions}

Excluded were 178 workers who were under medication for cardiovascular disease and 732 workers who failed to complete the questionnaire relating to noise annoyance and distress symptoms, mainly because of language difficulties. Thus 1587 healthy workers were included in the analysis.

\section{Interview data}

Previous studies have shown that health-related behavior is associated with demographic variables such as age, race, and education in many countries (30, $31)$, including Israel (32-34). Thus information collected in personal interviews of every subject included age, education, and country of origin. These variables were examined not only as predictors of the use of hearing protection devices, but also as possible confounders of its relationship to noise exposure and noise annoyance. Education was defined by the number of years of formal schooling, divided into the following three categories: $<8,9-12$, and $>12$ years. Country of birth was classified into the four broad regions of Africa, Asia, Europe (eastern and western), and Israel. The origin of Israeli-born workers was based on father's country of birth. Detailed data was also obtained for the use of hearing protection devices. Hearing protection devices were not used by 1200 workers. Among the users, 100 used earplugs regularly, 42 used earmuffs regularly, 192 used earplugs most of the time, and 43 used earmuffs most of the time. For the statistical analyses, the subjects were dichotomized into hearing protection device users $(\mathrm{N}=387)$ and nonusers $(\mathrm{N}=1200)$.

\section{Measures}

Noise exposure levels. Ambient noise levels at each workstation were measured with an SL-215 sound level meter (Quest Electronics, Oconomovoc, Wisconsin, United States) (area sampling), tripod mounted and adjusted to a height of $150 \mathrm{~cm}$ from the floor. Noise levels were sampled twice a day (morning and afternoon) in winter and summer. Each sampling was taken for a 30 -min period during which 5 - 15 readings were taken (depending on noise fluctuations). Results were noted in decibels (A) and were averaged for each of the four sampling periods. Noise exposure level was defined by the geometric mean exposure across the four samplings. For the purpose of this study, the following two noise exposure levels were defined: low $[<85 \mathrm{~dB}(\mathrm{~A})]$ and 
high [>85 $\mathrm{dB}(\mathrm{A})]$. The latter is the level at which the use of hearing protection devices is required by regulation.

Noise annoyance. The degree of annoyance from noise at the workplace was assessed with the use of six four-point items adapted from Tarnopolsky et al (35). These items were "Does the noise disturb you?" (1 - not at all, 4 - very much); "How do you feel

Table 1. Use of hearing protection devices in relation to noise level.

\begin{tabular}{lccc}
\hline \multirow{2}{*}{ Noise } & $\begin{array}{c}\text { Workers } \\
\text { exposed }\end{array}$ & \multicolumn{2}{c}{$\begin{array}{c}\text { Using hearing } \\
\text { protection devices }\end{array}$} \\
\cline { 3 - 4 } & & $\mathrm{N}$ & $\%$ \\
\hline Low & 1235 & 237 & 19.2 \\
High & 352 & 150 & 42.6 \\
\hline
\end{tabular}

a $\geq 85 \mathrm{~dB}(\mathrm{~A})$.

Chi-square $(1)=81.58, P<0.0001$.

Table 2. Use of hearing protection devices in relation to education.

\begin{tabular}{lcrr}
\hline \multirow{2}{*}{ Education } & Total & \multicolumn{2}{c}{$\begin{array}{c}\text { Using hearing } \\
\text { protection devices }\end{array}$} \\
\cline { 3 - 4 } & & $\mathrm{N}$ & $\%$ \\
\hline$\leq 8$ years & 468 & 118 & 25.2 \\
$9-12$ years & 978 & 255 & 26.1 \\
$>12$ years & 141 & 14 & 9.9 \\
\hline
\end{tabular}

Chi-square $_{(2)}=18.86, P<0.0001$.

Table 3. Use of hearing protection devices in relation to origin.

\begin{tabular}{lcrc}
\hline \multirow{2}{*}{ Origin } & Total & \multicolumn{2}{c}{$\begin{array}{c}\text { Using hearing } \\
\text { protection devices }\end{array}$} \\
\cline { 3 - 4 } & & $\mathbf{N}$ & $\%$ \\
\hline Africa & 497 & 125 & 25.2 \\
Asia & 346 & 76 & 22.0 \\
Europe & 530 & 133 & 25.1 \\
Israel & 214 & 53 & 24.8 \\
\hline
\end{tabular}

Chi-square $_{\{3\}}=3.02$, not significant.

Table 4. Use of hearing protection devices in relation to age.

\begin{tabular}{lccc}
\hline \multirow{2}{*}{ Age (years) } & Total & \multicolumn{2}{c}{$\begin{array}{c}\text { Using hearing } \\
\text { protection devices }\end{array}$} \\
\cline { 3 - 4 } & & $\mathrm{N}$ & $\%$ \\
\hline $20-24$ & 123 & 21 & 17.1 \\
$25-34$ & 467 & 101 & 21.6 \\
$35-44$ & 468 & 136 & 29.1 \\
$45-54$ & 317 & 76 & 24.0 \\
$55-64$ & 212 & 53 & 25.0 \\
\hline
\end{tabular}

Chi-square $(4)=11.04, P<0.03$ about the noise level here?" ( 1 - not annoyed at all, 4 - very annoyed); "Does the noise make you feel so bad that you feel you cannot carry on working?" ( 1 - not true at all, 4 - very true); "Does the noise prevent you from paying attention to your work?" ( 1 - not at all, 4 - very much); "Does the noise interfere with communicating with other workers (talks, conversation)?" $((1-$ not at all, 4 - very much); and "Would your general feeling in the workplace improve without the noise?" $(1-$ it would not change, $4-$ it would improve a lot). The internal consistency (Cronbach's alpha) of this scale was 0.90 . Noise annoyance was trichotomized into low, moderate, and high, corresponding to the upper, middle, and lower thirds of the score distribution.

Somatic complaints. Somatic complaints were measured on a 12 -item inventory adapted from that presented by Caplan et al (36). Sample item: How often did you suffer from headaches in the last three months? The response scale ranged from 1 (never) to 4 (often). The total score was the summation of the responses over the 12 items. Cronbach's alpha was 0.84 .

Poststress irritability. This variable was assessed according to Glass \& Singer's work (37), which demonstrated that the outcome of exposure to prolonged stress, such as that experienced at work, can best be observed by various after effects, including irritability, occurring after exposure to the stressor is terminated. Irritability was measured by two items scored on a five-point scale ranging from 1 (not true at all) to 5 (very true), namely, "After a workday are you irritable or impatient, do you want to be left alone, are you very much bothered by noises around you (eg, television)?" and "When you come home from work, does it take you a long time to relax and do the things you like or have to do?" The total score was the summation of the responses over the two items. The correlation between these two items was 0.61 .

\section{Statistical methods}

Percentages were compared by means of the chisquare test. Cronbach's alpha was used as a measure of the internal consistency of the questionnaires. The multivariate analyses were carried out with the use of an analysis of variance and multiple logistic regression.

\section{Results}

The use of hearing protection devices in relation to noise exposure level and several demographic variables is shown in tables 1 through 4 . The percentage of workers using hearing protection devices at 
high noise exposure levels $[\geq 85 \mathrm{~dB}(\mathrm{~A})]$ was 42.6 , which is comparable with figures from other studies $(2,3)$. This finding reinforces the general observation that more than half of the workers exposed to noise levels liable to induce hearing loss do not use hearing protection devices. Interestingly, among workers exposed to low noise, $19.2 \%$ used hearing protection devices. The use of hearing protection devices was positively related to age $(\mathrm{P}<0.03)$, with compliance lowest in the youngest group (20 24 years); and it was unexpectedly inversely related to education $(\mathrm{P}<0.0001)$. Workers with less than 12 years of education used hearing protection devices 2.6 times more than those with higher education ( $\geq 12$ years). There was no association with ethnic origin.

The correlation between noise exposure level and noise annoyance (both taken as continuous variables) was 0.17 . This finding is consistent with findings in many studies that this kind of correlation is usually rather low (seldom exceeding 0.25 ), independent of the exposure index employed $(6,18,38)$. Thus noise exposure level and noise annoyance can be considered to be two independent variables. With regard to our major study hypothesis, support was found for the positive association between noise annoyance and the use of hearing protection devices among workers exposed to low noise levels [chi square(2) $=50.47, \mathrm{P}<0.0001]$ and high noise levels [chi square $(2)=13.48, P<0.001]$. The breakdown of percentages of workers using hearing protection devices in both noise levels by noise annoyance is presented in figure 1.

This breakdown shows that the majority of hearing protection device users were workers highly annoyed by the noise. Among workers exposed to high noise levels, nearly $61 \%$ of the hearing protection device users came from the highly annoyed group. Among the workers exposed to low noise levels this was also the case. In this group, $59.7 \%$ of hearing protection device users were highly annoyed by the noise and preferred using hearing protection devices even though there was no immediate threat to their hearing.

The relationship of hearing protection device usage with noise exposure levels, noise annoyance lev$\mathrm{el}$, and their possible interactive effect was examined through multiple logistic regression analysis, with control for the possible confounders of age and education. No interaction between noise level and noise annoyance was found with respect to the use of hearing protection devices, and it was thus removed from the analysis. The results are shown in table 5. The use of hearing protection devices was independently related to noise exposure $(\mathrm{P}<0.0005)$, moderate noise annoyance $(\mathrm{P}<0.05)$, and high noise annoyance $(\mathrm{P}<0.0005)$, even after control for age and education. Inspection of the odds ratios indicated that high noise annoyance had a greater weight in influencing hearing protection device usage than the noise level.
Finally, we examined whether the use of hearing protection devices would alter the distress symptoms of somatic complaints and poststress irritability among the noise-annoyed workers. This possibility was tested by two-way analyses of variance including noise annoyance (three levels), the use of hearing protection devices (yes and no), and their interaction. For somatic complaints, significant effects were found for noise annoyance $[\mathrm{F}(2,1566)=46.7$, $\mathrm{P}<0.001]$, the use of hearing protection devices $[\mathrm{F}(1,1566)=7.00, \mathrm{P}<0.009]$, and their interaction $[\mathrm{F}(2,1566)=63.94, \mathrm{P}<0.01]$. For poststress irritability, significant effects were found for noise annoyance $[F(2,1047)=76.11, P<0.001]$ but not for the use of hearing protection devices $[\mathrm{F}(1,1047)=2.09$, not significant]. However, the interaction between noise annoyance and the use of hearing protection devices was significant $[F(2,1052)=6.11 \mathrm{P}<0.003]$. Both interactions are illustrated in figure 2.

Figure 2 illustrates how the mean scores for somatic complaints and poststress irritability increase concomitantly with noise annoyance. The use of

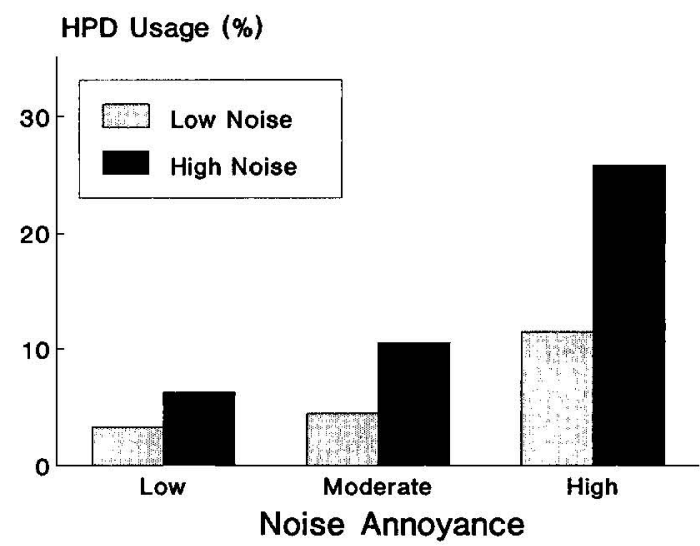

Figure 1. Use of hearing protection devices by noise annoyance and noise exposure level.

Table 5. Results of the multiple logistic regression for the use of hearing protection devices (yes $=1$, no $=2$ ) by noise level, noise annoyance level, age, and education. $(95 \% \mathrm{Cl}=95 \%$ confidence interval)

\begin{tabular}{lcc}
\hline Variable & Odds ratio & $95 \% \mathrm{Cl}^{\mathrm{a}}$ \\
\hline Noise level (high, low) & $2.94^{* *}$ & $2.58-3.30$ \\
Moderate annoyance $^{\mathrm{a}}$ & $1.43^{*}$ & $1.11-1.75$ \\
High annoyance $^{\mathrm{a}}$ & $3.03^{* *}$ & $2.77-3.29$ \\
Age & 1.00 & $0.99-1.01$ \\
Education & & \\
$\quad \leq 8$ years & & \\
$\quad 9-12$ years $^{\mathrm{b}}$ & $2.23^{*}$ & $1.60-2.86$ \\
\hline
\end{tabular}

a Compared with low annoyance.

b Compared with $>12$ years of education.

${ }^{*} \mathrm{P}<0.05,{ }^{* *} \mathrm{P}<0.0005$. 


\section{Somatic Complaints Score}

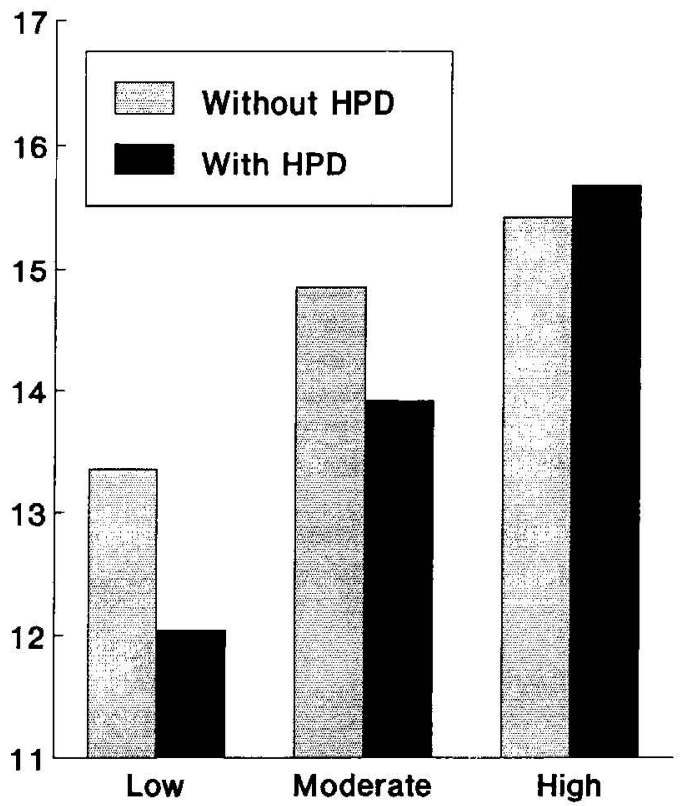

Noise Annoyance

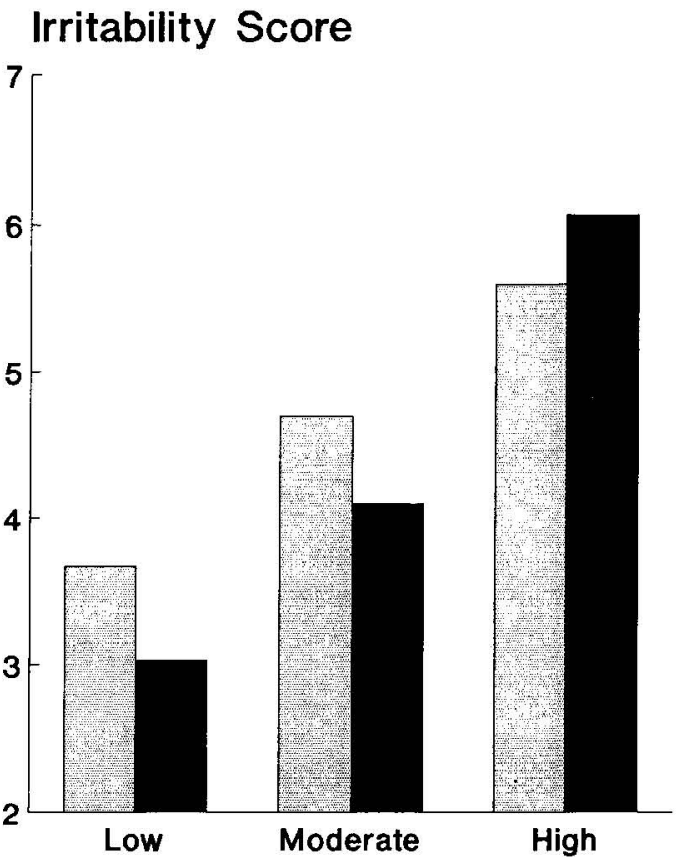

Noise Annoyance

Figure 2. Distress symptoms in workers differing in noise annoyance and use of hearing protection devices. (HPD $=$ hearing protection device)

hearing protection devices reduced both distress symptoms, but only among workers reporting low or moderate noise annoyance. Posthoc contrasts applied to these data indicated that, except for the irritability scores of low noise annoyance workers, all differences were significant at the $\mathrm{P}<0.05$ level or more. Contrary to expectation, high noise annoyance workers using hearing protection devices disclosed greater distress, statistical significance being reached for poststress irritability $(\mathrm{P}<0.01)$.

\section{Discussion}

The use of hearing protection devices in the presence of high noise levels $[\geq 85 \mathrm{~dB}(\mathrm{~A})]$ liable to cause hearing loss was examined in a large sample of healthy male blue-collar workers. Consistent with a previous finding (5), the use of hearing protection devices was associated with noise annoyance. Of the workers exposed to high noise levels, only $42.6 \%$ regularly used hearing protection devices, of whom $60 \%$ were highly annoyed by noise. Furthermore, noise-annoyed workers also tended to wear hearing protection devices even in low noise levels, when they were not required by regulation to do so. Thus a major contributor to hearing protection device usage was noise annoyance. This finding was further supported both by the high weight of noise annoyance in the logistic regression analysis and by the fact that there was no interaction between noise exposure and noise annoyance.

Given the previously discussed association between noise annoyance and stress reactions to noise, a major motive for using hearing protection devices could be the reduction of noise stress. When this assertion was directly tested, the use of hearing protection devices was significantly associated with a reduction in distress symptoms among the low and moderately annoyed workers, but not among the highly annoyed workers. A reduction in the noise level brought about by the use of hearing protection devices probably explains the reduced somatic complaints and irritability in the low and moderately annoyed groups. However, for the highly annoyed workers, the use of hearing protection devices may be an additional source of stress due to the discomfort, irritation, and inconvenience of their use. Further studies should be undertaken to explore whether noise-annoyed workers tend also to find the use of hearing protection devices more stressful. Nevertheless, highly annoyed subjects continued using hearing protection devices despite the possible additional stress experienced. It seems that the use of hearing protection devices in this group is still considered better than not using them at all.

The strong association between noise annoyance and the likelihood of using a hearing protection device has rarely been addressed in most previous studies attempting to disclose the factors governing 
the use and nonuse of hearing protection devices. We propose that this important factor be incorporated into all future studies on the use of hearing protection devices. In addition this finding has important implications for intervention. Future intervention procedures should focus on unannoyed workers who are less likely to use hearing protection devices. Furthermore, the results of the multiple logistic regression indicated that the use of hearing protection devices was also not related to age, but it was independently and inversely associated with education. This finding was rather unexpected in the light of previous findings obtained from the same population, for which smoking and other risk factors were more prevalent among less educated workers (31). This difference may stem from the fact that health-related behavior (smoking, physical exercise, weight maintenance, alcohol consumption) is usually initiated and regulated by individuals themselves, whereas the use of hearing protection devices signifies compliance to external regulations. Further studies looking at this issue are warranted.

Finally, our findings revealed that, even among the noise-annoyed workers, a considerable proportion still did not use hearing protection devices. Further research should be done investigating the barriers to usage, which in this group, may be stronger than the extent of suffering from the noise itself.

\section{Acknowledgments}

This study was supported by the Committee for Preventive Action and Research in Occupational Health, The Ministry of Labor and Social Affairs, Jerusalem, Israel.

The authors wish to thank Ms D Goffer for her assistance with the statistical analysis and Ms R Kasan for preparing the manuscript.

\section{References}

1. Abel SM. Noise-induced hearing loss and hearing protective devices. Can J Public Health 1986;77:104-7.

2. Baver P, Korpert K, Neuberger M, Raber A, Schwetz F. Risk factors for hearing loss at different frequencies in a population of 47388 noise exposed workers. Acoust Soc Am 1991;90:3086-98.

3. Chavalitsakulchai P, Shanavaz H. The need for a participatory conservation programme for the reduction of noise exposure to Thai female workers. Asia Pacific J Public Health 1989;3:310 - 4.

4. Abel AM, Kunov H, Pichora-Fuller MK, Alberti PW. Signal detection in industrial noise: effects of noise exposure history, hearing loss and the use of ear protection. Scand Audiol 1985;14:161-73.

5. Vihma $T$, Nurminen $M$. Noise in small industry. Int Arch Occup Environ Health 1983;52:191-6.

6. Van Dijk FJH, Souman AM, De Vries FF. Non-auditory effects of noise in industry: VI. a final field study on industrial noise and blood pressure. Int Arch Environ Health 1987;59:133-45.

7. Zohar D, Cohen A, Azar N. Promoting increased use of ear protectors through information feedback. Hum
Factors 1980;22:69-79.

8. Feldman RHL. The assessment and enhancement of health compliance in the workplace. In: Everly GS, Feldman RH, editors. Occupational health promotion: health behavior in the workplace. New York, NY: Wiley, 1985:33-46.

9. Robertson LS. Injury prevention: limits to self protective behavior. In: Weinstein ND, editor. Taking care: understanding and encouraging self protective behavior. Cambridge (England): Cambridge University Press, 1987:281-95.

10. Forrest MR. Protecting hearing in a military establishment. Scand Audiol Suppl 1982;16:7-12.

11. Hager WL, Hoyle ER, Hermann ER. Efficacy of enforcement in an industrial hearing conservation program. Am Ind Hyg Assoc J 1982;43:455-65.

12. Hempstock TI, Hill E. The attenuation of some hearing protectors used in the workplace. Ann Occup Hyg 1990;34:453-70.

13. Royster LH, Holder SR. Personal hearing protection: problems associated with the hearing protection phase of the hearing conservation program. In: Alberti PW, editor. Personal hearing protection in industry. New York, NY: Raven Press, 1982:447-69.

14. Kamal AA, Sayed GM, Hussan MH, Massoud AA. Usage of personal protective devices among Egyptian industrial workers. Am J Ind Med 1988;13:707-16.

15. Royster LH. Hearing protection devices and the real world. In: Royster LH, Hart FD, Stewart WD, editors. Proceedings of the 1981 national conference on noise control engineering, Raleigh, NC, 1981. New York, NY: Noise Control Foundation, 1981:161—4.

16. Nixon $\mathrm{CW}$. Hearing protective devices: ear protectors. In: Harris CM, editor. Handbook of noise control. New York, NY: McGraw Hill, 1979:12.1-13.

17. Lofgreen $\mathrm{H}$, Holm $\mathrm{M}$, Tengling $\mathrm{R}$. How to motivate people in the use of their hearing protectors. In: Alberti PW, editor. Personal hearing protection in industry. New York, NY: Raven Press, 1982:485-90.

18. Cohen S, Evans GW, Stokols D, Krantz DS. Behavior, health and environmental stress. New York, NY: Plenum, 1986.

19. Van Dijk FJH. Non-auditory effects of noise in industry: II. a review of the literature. Int Arch Environ Health 1986;58:325-32.

20. McLean EK, Tarnopolsky A. Noise, discomfort and mental health. Psychol Med 1977;7:19-62.

21. Melamed S, Najenson T, Luz J, Jucha E, Green M. Noise annoyance, industrial noise exposure and psychological stress symptoms among male and female workers. In: Berglund B, Berglund U, Karlsson J, Lindvall $\mathrm{T}$, editors. Proceedings of the 5 th international congress on noise as a public health problem; vol 2. Stockholm: Swedish Council for Building Research; 1988:315-20.

22. Kjellberg A. Subjective, behavioral and psychophysiological effects of noise. Scand J Work Environ Health 1990;16 suppl 1:29-38.

23. Ortiz GA, Arguelles AE, Crespin HA, Sposari G, Villafane CT. Modification of epinephrine, norepinephrine, blood lipid fractions and the cardiovascular system produced by noise in an industrial medium. Horm Res 1974;5:57-64.

24. Ising $H$, Dienel $D$, Gunther $T$, Markert B. Health ef fects of traffic noise. Int Arch Occup Environ Health 1980;47:179-90.

25. Andren L, Lindstedt G, Bjorkman M, Borg KO, Hansson L. Effect of noise on blood pressure and 'stress' hormones. Clin Sci 1982;62:137-41.

26. DeJoy DM. A report on the status of research on the cardiovascular effects of noise. Noise Control Eng $J$ 1984;23:32-9.

27. Stansfeld SA, Clark CR, Jenkins LM, Tarnopolsky A. Sensitivity to noise in a community sample: I. mea- 
surement of psychiatric disorder and personality. Psychol Med 1985;15:243-54.

28. Melamed S, Luz J, Green MS. Noise exposure, noise annoyance and their relation to psychological distress, accident and sickness absence among blue collar workers in the CORDIS Study. Isr J Med Sci 1992;28: $629-35$.

29. Ohrstrom E, Bjorkman M, Rylander R. Noise annoyance with regard to neurophysiological sensitivity, subject noise sensitivity and personality variables. Psychol Med 1988;18:605-13.

30. Fiore MC, Novotny TE, Pierce JP, Hatziandrev EJ, Patel KM, Davis RM, et al. Trends in cigarette smoking in the United States. The changing influence of gender and race. JAMA 1989;261:49—55.

31. Ford ES, Merritt, RK, Heath, GW, Powell KE, Washburn RA, Kriska A, Haile G. Physical activity behaviors in lower and higher socioeconomic status populations. Am J Epidemiol 1991;133:1246-56.

32. Goldbourt U, Medalie JH. Characteristics of smokers, non-smokers and ex-smokers among 10,000 adult males in Israel: I. distribution of selected sociodemographic and behavioral variables and the prevalence of disease. Isr J Med Sci 1975;11:1079-101.

33. Green MS, Harari G. Past and present smoking behaviour and its association with health-related habits in selected Israeli working populations: the Cordis study. Int J Epidemiol 1992;21:494-501.

34. Green MS, Jucha E, Luz J. Ethnic differences in selected cardiovascular disease risk factors in Israeli workers. Isr J Med Sci 1985;21:808-16.

35. Tarnopolsky A, Barker SM, Wiggins RD, McLean EK. The effect of aircraft noise on the mental health of a community sample: a pilot study. Psychol Med 1978;8: 219-33.

36. Caplan RD, Cobb S, French JRP Jr, Van Harrison R, Pinneau SR Jr. Job demands and worker health: main effects and occupational differences. Washington DC: Department of Health, Education and Welfare, 1975. Report to National Institute for Occupational Safety and Health; HEW publication no. (NIOSH) 75-160.

37. Glass DC, Singer JE. Urban stress: experiments on noise and social stressors. New York, NY: Academic Press, 1972.

38. Rylander R, Bjorkman M, Ahrlin U, Arntzen E, Solberg $\mathrm{S}$. Dose-response relationships for traffic noise and annoyance. Int Arch Occup Environ Health $1986 ; 41: 7-10$.

Received for publication: 10 December 1993 